\title{
Bancada Virtual SIMP II - um caso de sucesso
}

DOI: 10.37702/2175-957X.COBENGE.2021.3736

Sergio Adalberto Pavani - sapavani@ctism.ufsm.br

UFSM

TENENTE CORONEL BRITO 220

96810-202 - Santa Cruz do Sul - RS

Gilberto João Pavani - gilberto.pavani@restinga.ifrs.edu.br

Instituto Federal do Rio Grande do Sul

Rua Coronel Massot 1229

91910-530 - PORTO ALEGRE - RS

Resumo: $O$ processo de ensino/aprendizagem nas engenharias sofre de um processo cada vez maior de fragmentação. A especificidade dos cursos é cada vez mais acentuada o que gera uma multiplicidade de meios de para a formação discente. 0 foco deste trabalho é para a disponibilização dos meios para que o aluno possa ter um acesso às tecnologias e colocar em prática as experiencias e ensaios necessários para compreender, saber aplicar e desenvolver técnicas diversas nas áreas de movimento envolvendo a pneumática, hidráulica, acionamentos elétricos e os controladores de processo. As maiores limitações para que o corpo docente e discente dos diversos institutos envolvidos no ensino da tecnologia industrial é a disponibilização dos recursos materiais na quantidade e diversidade necessária para a formação do técnico, tecnólogo e do engenheiro e mais importante do que isto é a necessidade de integração destas tecnologias o que é praticamente impossível devido ao fato que os laboratórios normalmente são especializados, como os de pneumática, ou acionamento de motores ou de controladores de processo (automação). Isto leva ao ensino compartimentado, fragmentado o que é indesejado, pois tanto o discente tem dificuldade para compreender o todo de um processo, como o docente apresenta dificuldades para expor um processo industrial mais complexo aos estudantes.

Palavras-chave: Automação. Laboratório virtual. Pneumática. Eletropneumática . Inovação no Ensino. 


\section{BANCADA VIRTUAL SIMP II - UM CASO DE SUCESSO}

\section{INTRODUÇÃO}

O processo de ensino/aprendizagem (EA)é um sistema fragmentado, quando podemos olhar o objetivo de um curso de formação tecnológica. Esta fragmentação é entendida como obrigatória, pois as tecnologias são cada vez mais complexas e vastas e a maneira de entende-las é dividir nas porções que são julgadas adequadas a este processo de EA, assim como os diversos cursos deste a formação técnica até o ensino superior. Na metade do século 20 o ensino técnico industrial era dividido praticamente entre os cursos de mecânica e eletrotécnica e em 50 anos esta divisão acrescentou mais de uma dezena de denominações, complementando as exigências da indústria, do comércio e da sociedade. Esta mesma diversidade acontece nos cursos de engenharia

E qual a consequência disto?

A consequência a nível institucional é a necessidade da formação de um conjunto de cursos diversos e ainda multiplicado por ênfases conforme verificado e determinado pelas instituições e sociedade, ainda limitado pelos ministérios comprometidos com a ciência, tecnologia e cultura de uma nação.

Ao ser determinado o(s) cursos(s) de uma instituição passa a ser montada a estrutura curricular dividindo o curso em suas disciplinas, com a consequente formação do corpo docente e a busca da implantação dos recursos de ensino, sendo os laboratórios os pontos de importância significativa, pois normalmente precisarão de áreas grandes, equipamentos onerosos e ainda é necessário definir a abrangência (até que nível serão ofertados os ensaios) e de que modo serão disponibilizados os ensaios, ou seja, será o laboratório composto por equipamentos únicos ou múltiplos.

No caso dos laboratórios compostos por equipamentos únicos, certamente estes estarão destinados ao processo de demonstração para os alunos dos cursos de graduação e talvez para desenvolvimento de experiencias para docentes e de pequenos grupos de pesquisa. Neste caso estes laboratórios serão menores, de baixo custo de implantação e, consequentemente de muito pequeno impacto na formação do aluno, pois ele não poderá efetivamente ter contato com a tecnologia oferecida.

Quando visualizamos laboratórios com equipamentos múltiplos, vamos observar grandes áreas, investimentos também grandes em equipamentos e consequentemente em manutenção e atualização deste. Neste caso, o aluno poderá ter um contato intimo com a tecnologia proporcionada pelo laboratório, entretanto surge uma limitação adicional. Esta limitação está na capacidade do docente de atender satisfatoriamente ao conjunto dos alunos que irão demandar este. Assim este laboratório somente poderá ser utilizado quando o docente responsável estiver com disponibilidade ou um técnico competente poder trabalhar com os alunos. Porém caso isto não seja possível (assistência disponível para uso do laboratório) o aluno será impedido de utilizar o laboratório, seja por questões didáticas, patrimoniais e/ou de segurança física.

\subsection{A busca de soluções para os laboratórios de aprendizagem na área tecnológica}

Neste trabalho não será discutido a necessidade e importância dos laboratórios de pesquisa. 
Fica claro e definido que os laboratórios de ensino nas áreas tecnológicas são instalações de alto custo de implantação e manutenção, porém inegavelmente necessários, pois as instituições que não podem oferecer estes laboratórios, o processo de EA fica fragilizado e mesmo aquelas instituições que disponibilizam laboratórios qualificados, não conseguem atender a todas as necessidades dos estudantes, pois alguns destes alunos necessitam um tempo maior junto às instalações didáticas para compreender e apreender as tecnologias necessárias para a sua formação completa. De outro lado está a disponibilidade do corpo docente ou o pessoal de apoio, como os Técnicos em Assuntos Educacionais (TAE), Auxiliares de Laboratórios ou monitores, pois o tempo livre de alguns alunos é incompatível com os horários disponibilizados com a instituição.

Em um caso específico de experimentos voltados à acionamentos (pneumáticos, hidráulicos, motores, etc), que é o foco deste trabalho, são experimentos práticos que demandam um tempo relativamente grande para a sua execução e também envolvem grande quantidade de recursos (cabos, mangueiras, atuadores, fontes, a bancada onde é montado o experimento, etc) e que não pode ficar montado aguardando uma análise por parte do corpo docente envolvido, pois certamente será necessário para a próxima turma que o utilizará ou para as atividades de manutenção/calibração/etc, por parte dos TAE's ou uma nova aula com outro docente.

Após esta análise, mesmo que superficial, pode-se afirmar que uma das necessidades básicas na formação dos técnicos, tecnólogos e engenheiros da área industrial é a experimentação ou o uso dos laboratórios ligados a acionamentos (pneumática, hidráulica, motores, CLP's, etc) e a integração destas tecnologias, que podem ocorrer de diversas maneiras, sendo que uma delas é o uso de bancadas virtuais.

Deve ser observado que uma bancada virtual é diferente de um simulador didático em alguns aspectos de principalmente quanto a apresentação, como será visto no próximo bloco.

\section{DESENVOLVIMENTO E APRESENTAÇÃO DE RESULTADOS}

A meta do trabalho inicial era desenvolver um sistema utilizando computadores que o aluno pudesse "enxergar" uma bancada didática de pneumática, o mais próximo possível das instalações reais de um laboratório didático, na tela de um computador, onde as ligações pudessem comportar-se como estas.

Neste ponto deve ser montada a equipe adequada, que inicialmente ficou formada por um coordenador, um especialista em programação e com experiencia didática (aquele que deve gerar o programa e as imagens com comportamento idêntico ao de uma bancada didática real) e um especialista em sistemas pneumáticos, também com experiencia didática e com grande experiencia prática na operação de sistemas para que a análise comportamental de um sistema virtual pudesse ser testado e analisado. Formada a equipe base, inicia-se a integração, obrigando a uma grande troca de experiencias e a elaboração das especificações do sistema.

Para a primeira versão, foi dimensionado um sistema mínimo puramente pneumático com componentes mínimos, mas que pudesse permitir a realização de ensaios completos.

\subsection{A configuração da primeira versão da bancada virtual}


Para permitir esta operação mínima foram selecionados elementos que permitissem ensaios de operação e ao mesmo tempo pudesse ser um desafio para alunos e uma ferramenta eficiente para o corpo docente e consequentemente para as instituições de ensino.

A configuração definida para uma bancada virtual puramente pneumática foi definida pela equipe conforme listado abaixo:

a- Cilindro de dupla ação;

b- Cilindro de simples ação com retorno por mola;

c- Um alimentador de ar, necessário para alimentar com "ar comprimido" o sistema;

d- Uma válvula de comando com atuador manual tipo trava, com knob curto, três vias e duas posições;

e- Uma válvula de comando com atuador manual tipo botão com retorno por mola, três vias e duas posições, NF (normalmente fechada);

f- Uma válvula de comando com atuador manual tipo trava, com alavanca, cinco vias e duas posições;

g- Uma válvula de controle direcional duplo piloto, cinco vias e duas posições;

h- Uma válvula de controle direcional piloto/mola, cinco vias e duas posições;

i- Um elemento lógico $\mathrm{E}$, ou válvula de simultaneidade;

j- Um elemento lógico OU, ou válvula alternadora;

k- Um conector T, que permite derivar conexões;

I- Um tampão, que permite fechar conexões que devem ser fechadas,

m- Válvulas de comando com atuador mecânico tipo rolete com retorno por mola, três vias e duas posições, NF (normalmente fechada), sendo que estas válvulas sempre estarão disponíveis nas extremidades dos atuadores;

Estes componentes são disponibilizados no menu esquerdo da Bancada Virtual, e do lado direito um conjunto de Comandos listados abaixo, na Tabela 1

Tabela 1- Símbolos de apoio da Bancada Virtual

\begin{tabular}{|c|c|}
\hline SIMBOLO & SIGNIFICADO/AÇÃO \\
\hline & $\begin{array}{l}\text { Manômetro. Liga e desliga a disponibilidade do ar comprimido. } \\
\text { Na cor verde- desligado. Na cor vermelha- ligado. } \\
\text { Para ligar/desligar o ar comprimido clicar sobre o símbolo. } \\
\text { Nota: para o ar comprimido estar disponível é necessário a fonte de ar comprimido. }\end{array}$ \\
\hline & $\begin{array}{l}\text { Borracha. } \\
\text { Apaga as mangueiras e ligações elétricas. } \\
\text { Para apagar as ligações, clicar sobre o símbolo. }\end{array}$ \\
\hline & $\begin{array}{l}\text { Estrela. } \\
\text { Símbolo que deve ser usado com cuidado. APAGA TODA A TELA }\end{array}$ \\
\hline & $\begin{array}{l}\text { Arquivo. } \\
\text { Salva um arquivo }\end{array}$ \\
\hline & $\begin{array}{l}\text { Pasta. } \\
\text { Abre arquivos existentes }\end{array}$ \\
\hline & $\begin{array}{l}\text { Lixeira. } \\
\text { Um símbolo arrastado para a lixeira é excluído }\end{array}$ \\
\hline
\end{tabular}




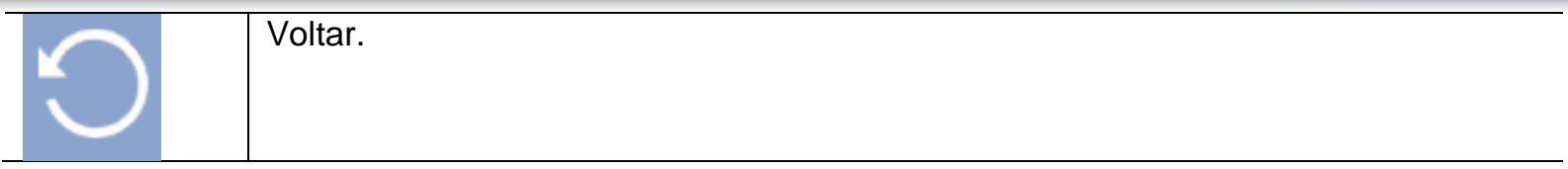

A bancada Virtual foi denominada como SIMP e possui a configuração inicial conforme a Figura 2.

Figura 2- Configuração Inicial

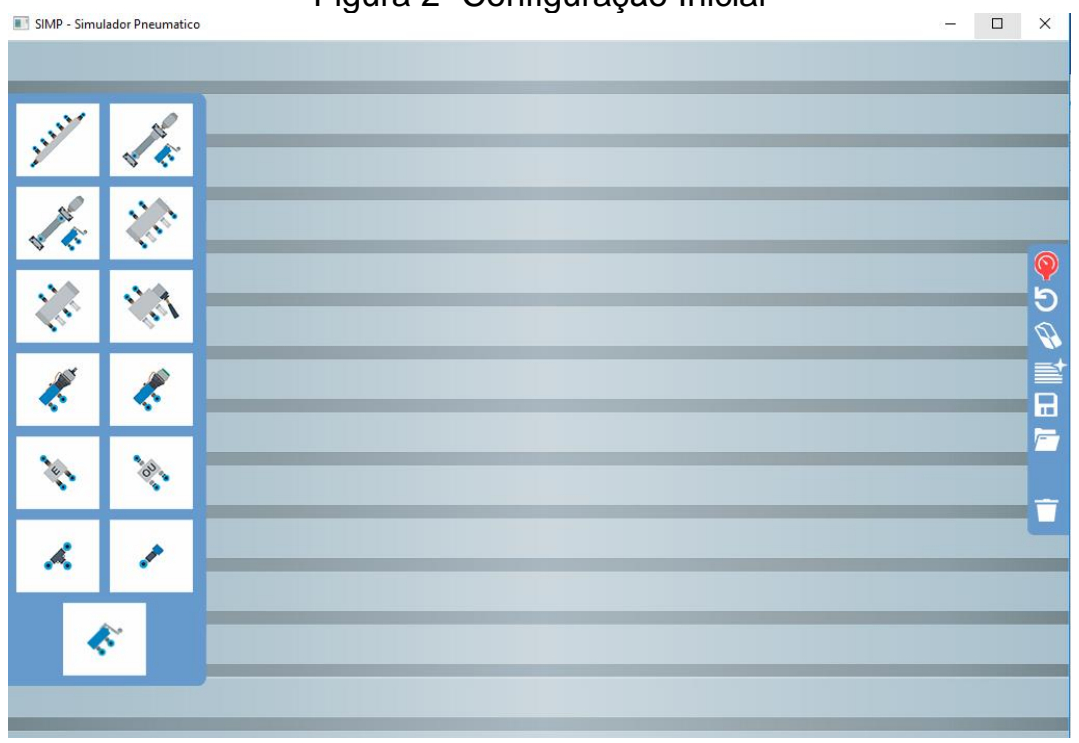

Fonte: autores

Após a montagem dos componentes a Bancada Virtual SIMP, pode operar através de clics do mouse ou com as mãos em uma tela de toque, conforme a figura 2.

Figura 2 - Sistema pneumático montado

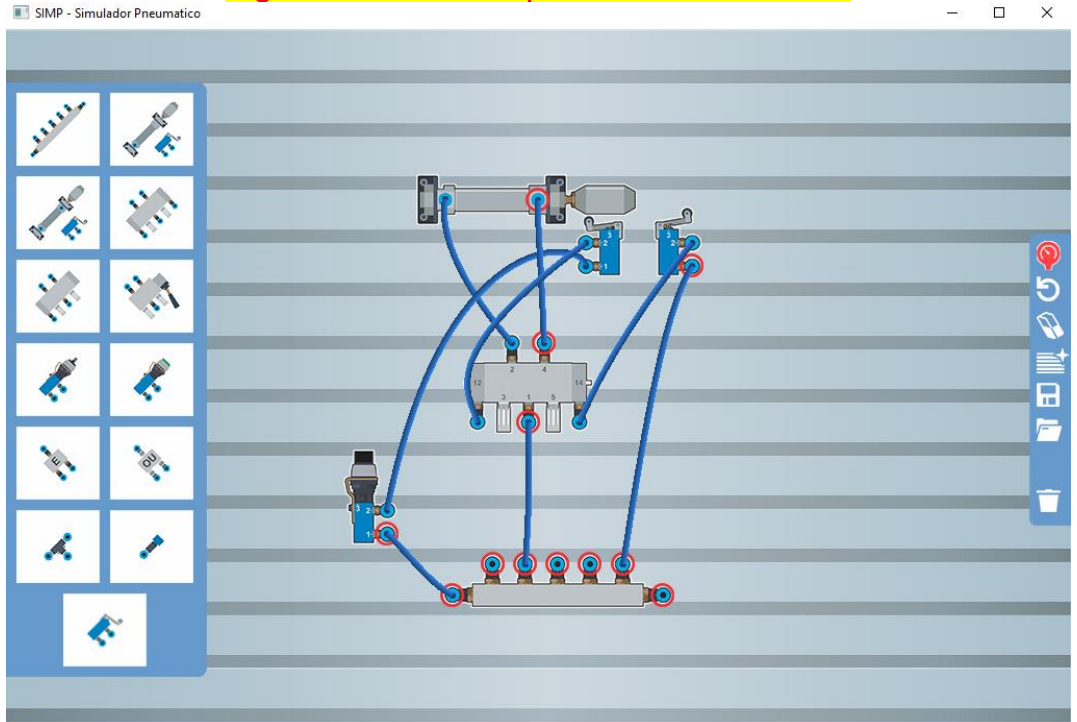

Fonte: autores

$\mathrm{Na}$ figura 2 está montado um sistema simples, composto por um único cilindro e algumas válvulas, porém cada um dos elementos pode ser multiplicado indefinidamente, o que não ocorre em uma bancada didática física, o que limita os tipos de exercícios a serem elaborados, também limitando a possibilidade de desenvolver circuitos complexos 
por alunos e professores. Desta maneira a Bancada Virtual SIMP permite um amplo espectro no processo de EA.

A Bancada Virtual SIMP ainda oferece informações visuais sobre zonas pressurizadas, zonas de baixa pressão, descarga de ar e vazamentos e onde podem ser montados circuitos complexos como o mostrado na Figura 3 , ou até o limite da necessidade de cada um.

Figura 3- Circuito pneumático com três cilindros simultaneidade e emergência

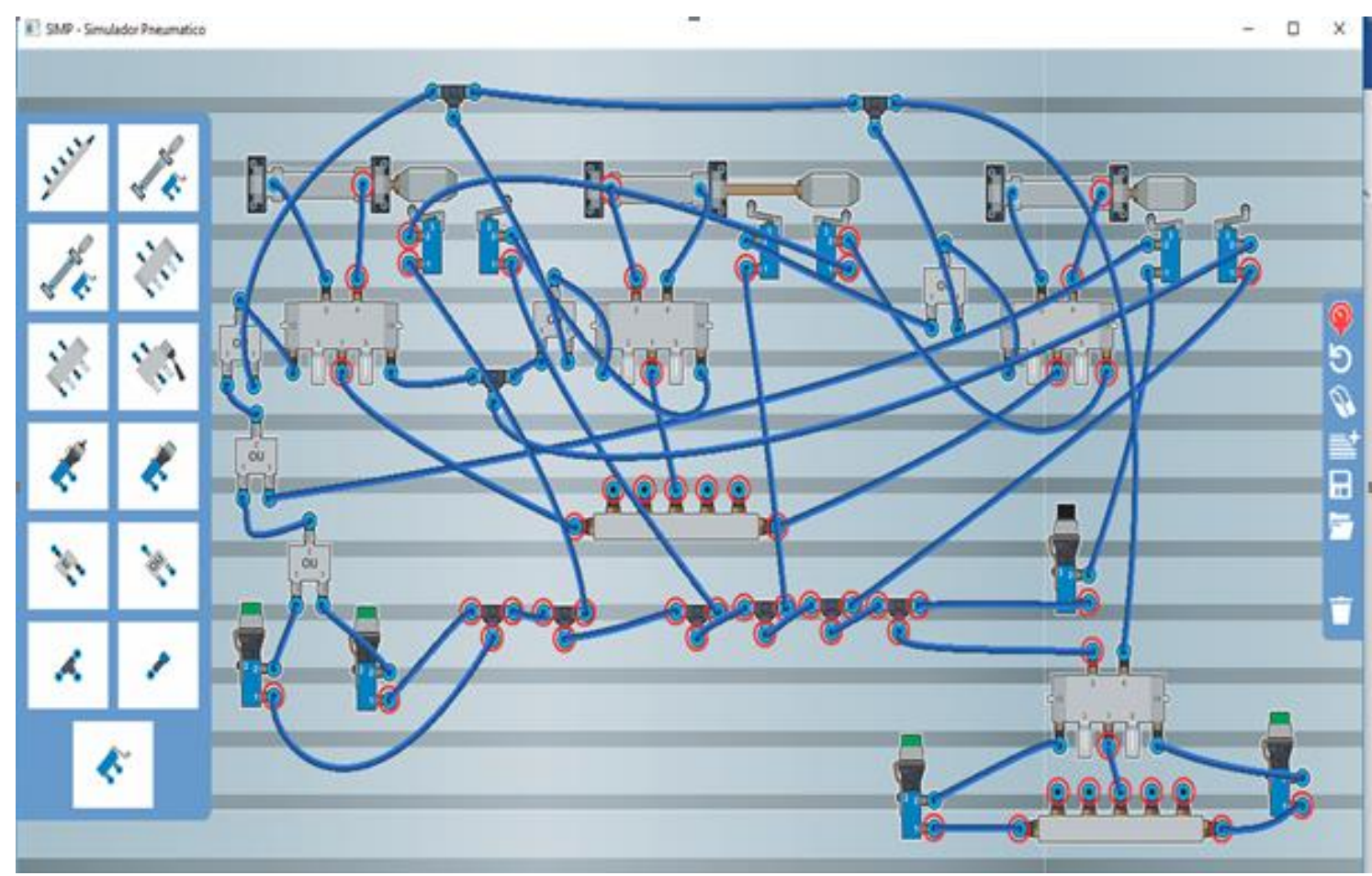

Fonte: autores

Vamos colocar as vantagens do uso da Bancada Virtual SIMP na forma de tópicos. Devemos ressaltar que os dispositivos físicos (reais) não poderão ser abandonados, podendo e devendo ser ainda utilizados, mas os dispositivos virtuais, como a Bancada Virtual SIMP, são e cada vem mais serão indispensáveis, sendo as vantagens do uso da Bancada Virtual SIMP:

1- É uma ferramenta acessível, podendo inclusive ser utilizada por pessoas com deficiências;

2- O uso da Bancada Virtual SIMP será individual, permitindo que o estudante tenha o tempo que precisar para experimentar e comprovar o funcionamento do circuito;

3- Pode ser utilizado em computadores pessoais;

4- É barato de implantar;

5- Existe um manual para auxiliar o estudante e o professor;

6- Logo estará disponível a nova versão (SIMP II), com sistemas eletropneumáticos.

As experiencias realizadas com alunos (aproximadamente 300 alunos) durante 3 anos, utilizando esta versão, ficou demonstrado que a transferência dos conhecimentos 
para uma bancada real ficou mais fácil. Alguns alunos utilizando somente a Bancada Virtual SIMP conseguiram montar circuitos em uma bancada didática real sem auxílio.

\section{CONCLUSÃO}

Os módulos previstos para a Bancada Virtual SIMP e o seu estado atual estão listados abaixo:

- MÓDULO I -Pneumática pura - liberado para uso universal;

- MÓDULO II - Pneumática pura, Eletropneumática e comandos elétricos para motores trifásicos de uma tensão - desenvolvimento final;

- Eletropneumática proporcional - previsto;

- Hidráulica pura - previsto;

- Eletrohidráulica - previsto;

- Hidráulica proporcional - previsto;

- Comandos Elétricos para motores de multitensão e sistemas de proteção previsto;

- Controladores de Processo - previsto.

Para a elaboração dos dois módulos iniciais, foram 4 anos de trabalho, pois por alguns momentos foi possível montar uma real equipe de trabalho, mas a maior parte do trabalho certamente foi uma atividade quase que solitária.

Porém este projeto exige uma equipe multidisciplinar com os seguintes componentes:

- Especialistas na área de produção do software - o mais importante;

- Especialista no ensino e uso de sistemas pneumáticos e hidráulicos nas suas versões de acionamento puro (e musculares), com acionamento elétricos (eletropneumática e eletrohidráulica) e as versões com comando proporcional (as mais complexas);

- Especialistas no acionamento e proteção de motores trifásicos CA (corrente alternada);

- Especialistas em controladores de processo;

- E finalmente aqueles que podem congregar todos estes elementos, o especialista em processo, que irá fechar todo o circuito necessário para a montagem de um sistema automatizado.

Mais ainda, como se trata de um programa de computador que deve ser facilmente visualizado e os seus elementos identificados de uma maneira fácil e as sus imagens certamente deverão ser "customizadas" conforme regiões a serem abrangidas, o designer gráfico serão responsável pelo acabamento visual e ainda na participação dos efeitos de sons, que darão vida e entusiasmo ao produto: a Bancada Virtual SIMP I e SIMP II. Desta maneira a Bancada Virtual SIMP I e SIMP II poderão formar desde o eletricista industrial na preparação de motores para uma pequena instalação, passando pelo ensino profissionalizante (formação continuada), ensino técnico e tecnológico até atingir os sistemas integrados de ensino na área industrial e automação comercial e residencial. Isto tudo com a vantagem ou talvez a única possibilidade existente no mercado de integração destas tecnologias, com possibilidades adicionais.

Portanto, através desta descrição das necessidades ficam listados os profissionais necessários para a continuidade deste programa com um valor a ser investido de $R \$$ 2.000.000,00 


\section{1- Justificativa}

A continuidade do desenvolvimento e a disseminação sistemática do programa Bancada Virtual SIMP I e SIMP II é uma necessidade para que o ensino e aprendizagem das tecnologias de movimento e automação sejam de fácil acesso, pois os laboratórios necessários para o processo de ensino e aprendizagem destas técnicas são de cara implantação e manutenção.

Os laboratórios voltados ao ensino de pneumática, hidráulica, comandos e proteção de motores elétricos e controladores de processos normalmente são segmentados e não integrados, porém a Bancada Virtual SIMP I e SIMP II permitirão esta integração a um baixo custo, caso existam os financiamentos necessários para o seu desenvolvimento. Também deve ficar patente que além do ensino presencial, o ensino a distância, ou o ensino integrado que poderá associar o ensino a distância com 0 presencial.

Outro item que deve ser considerado é que o ensino virtual e o físico em laboratórios poderão ser integrados, permitindo que poucos recursos físicos sejam utilizados por muitos alunos, pois as bases e o desenvolvimento poderão ser executados na Bancada Virtual SIMP I e SIMP II, assim como os alunos poderão utilizar este programa em suas residências ou até mesmo em outras mídias.

$O$ volume de alunos no Brasil a serem atingidos pelo programa Bancada Virtual SIMP I e SIMP II pode ser avaliado pelos números da ABENGE abaixo. A ABENGE (Associação Brasileira de Educação em Engenharia) em 2017 listou 5.583 cursos de Engenharia no Brasil.

Conforme dados do INEP foi montada a Tabela 2 abaixo.

Tabela 2 - Formados em Engenharia em 2016

\begin{tabular}{l|l|l|l|l}
\hline $\begin{array}{l}\text { Número de } \\
\text { formandos }\end{array}$ & $\begin{array}{l}\text { Instituições de ensino } \\
\text { privado }\end{array}$ & \multicolumn{2}{|l}{ Instituições de ensino público } \\
\hline & Percentual & Número & Percentual & Número \\
\hline 100.421 & 71,58 & 71881 & 28,42 & 28540 \\
\hline
\end{tabular}

O maior número de formados foram em:

- Engenharia Civil $\quad 35.360$ formados

- Engenharia de Produção 17.344 formados

- Engenharia Mecânica 11.434 formados

- Engenharia Elétrica $\quad 9.728$ formados

Neste estudo não estão listados os alunos de Engenharia de Automação e de outros cursos relacionados, porém em um rápido apanhado, poderíamos listar nas instituições de ensino superior no Brasil mais de 40.000 alunos a serem beneficiados com este programa, sem incluir os formandos em Engenharia Civil, que também devem utilizar a parte de acionamentos elétricos.

Nas instituições de ensino federal com mais de 644 unidades de ensino técnico e tecnológico encontraremos quantidades ainda maiores de estudantes que poderão utilizar estas tecnologias, onde também poderão ser incluídos os alunos do Sistema S, notadamente o SENAI (Serviço Nacional de Aprendizagem Industrial) com unidades também espalhadas em todo o território nacional.

Também devemos lembrar que o Brasil, por seu porte, população e história, deve ser um desenvolvedor e disseminador de tecnologias, podendo utilizar programas como a Bancada Virtual SIMP para esta disseminação. Naturalmente esta não é uma novidade, pois os sistemas virtuais são uma realidade de implantação maciça em todos os meios da 
vida, pois não podemos mais falar em "tecnologia", pois estes sistemas abrangem muitos segmentos.

Finalmente, a Bancada Virtual SIMP é um produto criado e em desenvolvimento por Brasileiros que acreditam nesta nação e até o momento não mediram sacrifícios para que um dos segmentos tecnológicos possam ser acessados universalmente.

\title{
VIRTUAL WORKBENCH FOR PNEUMATIC, HYDRAULIC, ENGINE AND PROCESS CONTROLLERS AND AUTOMATION FOR TEACHING LABORATORIES - A SUCCESS CASE
}

\begin{abstract}
The teaching / learning process in engineering is undergoing an increasing movement of fragmentation. The specificity of the courses is more and more accentuated, generating a multiplicity of means for the student formation. The focus of this work is the provision of the means for the student to have access to emerging technologies and to put into practice the experiments and tests necessary to understand, apply and develop diverse techniques in the areas of action, involving pneumatics, hydraulics, drives electrical and process controllers. The greatest limitations for the student and teacher bodies as well as the various institutes involved in teaching industrial technology is the availability of material resources in the quantity and diversity necessary for the training of technician, technologist and engineer and, more importantly, is the need to integrate these technologies which is virtually impossible due to the fact that laboratories are usually specialized, such as pneumatics or motor drives or automation process controllers. This leads to compartmentalized, fragmented teaching that is undesired, since both the student has difficulty understanding the whole of a process, as the teacher presents difficulties to expose a more complex and current industrial process to students.
\end{abstract}

Keywords: Automation. Virtual laboratory. Pneumatics. Electropeneumatics. Innovation in Teaching. 